\title{
Validation of the criteria matrix about the generalist's education in Dentistry Undergraduate Courses
}

\author{
Luiz Roberto Augusto NORO(a) iD \\ Angelo Giuseppe Roncalli da \\ Costa OLIVEIRA(a) \\ Bruno César de Vasconcelos \\ GURGEL(b) \\ Pedro Henrique de ARAÚJO(c) \\ (a) Universidade Federal do Rio Grande do \\ Norte - UFRN, Programa de Pós-graduação \\ em Saúde Coletiva, Departamento de \\ Odontologia, Natal, RN, Brazil. \\ (b) Universidade Federal do Rio Grande do \\ Norte - UFRN, Programa de Pós-graduação \\ em Ciências Odontológicas, Departamento \\ de Odontologia, Natal, RN, Brazil. \\ (c) Universidade Federal do Rio Grande \\ do Norte - UFRN, Departamento de \\ Odontologia, Natal, RN, Brazil.
}

Declaration of Interests: The authors certify that they have no commercial or associative interest that represents a conflict of interest in connection with the manuscript.

Corresponding Author:

Luiz Roberto Augusto Noro

luiz_noro@hotmail.com

https://doi.org/10.1590/1807-3107bor-2021.vol35.0089

Submitted: March 28, 2020

Accepted for publication: October 8, 2020

Last revision: December 8, 2020
Abstract: The generalist training planned by Brazilian National Curriculum Guidelines for Dentistry undergraduate courses should provide actions for the development of health promotion in the field of public health, as well as disease prevention, diagnosis, planning, and dental treatment in the clinical field. Considering this complexity, the aim of the present study was to validate dimensions and sub-dimensions in dentistry training, allowing the identification of the main necessary competences and clinical skills for the generalist practice. For this, an evaluation study was carried out through the Delph's Method with the participation of 19 professors of Dentistry courses in Brazil working in the clinical area, considered "experts" in this theme. It was possible to identify clinical competences and skills in four dimensions and respective sub-dimensions: Transversal skills (biosafety, patient-team communication, humanization, ethical principles, dental documentation); Diagnosis and planning (diagnosis of dental caries, pulp and periapical changes, and periodontal diseases, clinical and imaging exam, and single treatment planning); Preventive activities (oral hygiene guidance and oral cancer prevention); and Dental care (anesthesia, basic oral surgery, drug prescription, subgingival scaling and root planing, dental restoration, minimally and non-invasive restoration treatment, and dental urgencies). The developed model represents a differentiated alternative for the construction of an innovative curriculum in Dentistry, aimed at the training of general practitioners to provide humanized, highly effective, and resolving care. The importance of clinical tutoring by professors on the essential clinical skills and abilities is highlighted in this study.

Keywords: Dentistry; Curriculum; Education.

\section{Introduction}

The National Curriculum Guidelines (DCN) for Dentistry undergraduate courses stipulates that students should receive a generalist, humanistic, critical, and reflective education, and dentists should be able to provide a whole-person healthcare. ${ }^{1} \mathrm{DCN}$ recommends that dentists must be trained to be aware of their role and their social responsibilities as healthcare providers for the most prevalent health problems of the population. ${ }^{2}$

Clearly defining the term "generalist" is a challenge for everyone who proposes to understand and apply the DCN. According to Furtado, ${ }^{3}$ 
besides the integration of disciplines, practices, and knowledge inherent to a profession, the generalist education must be centered on family and individual care. Under this perspective, having knowledge of social sciences is imperative in healthcare education, which will allow professionals to analyze situations and define strategies for social and healthcare practices transformation considering specific social groups. ${ }^{4}$

The generalist should develop actions in the field of public health (service management and health promotion), while performing disease prevention, clinical diagnosis, and dental treatment planning and execution. ${ }^{5}$ According to Krieger, ${ }^{6}$ a skilled generalist should be able to solve 80 to $85 \%$ of the most prevalent oral diseases.

A generalist education in healthcare still runs into sociocultural obstacles such as worse job opportunities and lower salaries and social prestige, aspects that show the lack of professional appreciation and hinder these professionals' employability. ${ }^{7}$

A generalist training is often seen as a preliminary education process that must be completed with specialization in the construction of a health professional. This profile is further defined within the decision-making processes, communication with peers and society, ability to lead change, and in the administrative and managerial abilities. The generalist formation also aims at permanent education in health care provision based on a broader sense of health, curricular integration and multidisciplinary work. ${ }^{8}$

However, the hegemonic pedagogical model perpetuates a compartmentalized and isolated content formation, based on the professor's previous education and clinical expertise, which fragmentizes the teaching process, encourages the premature specialization, driving the generalist and the community's needs apart. It would be central to lecturers to teach specific courses within the expanded concept of health and multidisciplinary integrated work, going beyond the technical aspects of the profession. ${ }^{9}$

The integration of dental specialties for the formation of a generalist still presents some limitations since the pedagogic culture of most Dentistry undergraduate courses is far from the proposal for an integrated curriculum. ${ }^{10}$
Likewise, the role of the process in the particular skills and abilities of professional education should extrapolate the expertise brought from clinical specialties in order to build a new profile grounded in the guidance of clinical procedures, which are fundamental for a professional education. ${ }^{4}$

The establishment of this referential demands a search for factors that outline the fundamental elements to be considered in the guidance of professors and in the making of curricula that improve the quality of Dental generalist programs. In addition, there should be monitoring of the attitude of professors, increasingly more limited to their specialties, and students, who continue to face problems at the school clinic where a fragmented technical knowledge is not solid enough to provide a solution. ${ }^{11}$

The present study had the objective to validate the dimensions and sub-dimensions of the generalist education and identify the main clinical skills and abilities to be developed by Dentistry undergraduate courses.

\section{Methodology}

The present evaluation research was characterized by being constituted of procedures that precede the evaluation process itself as of the preliminary and systematic exam regarding the satisfactory answers to a given problem situation, which supports its adoption in decision-making. ${ }^{12,13}$

This study aimed to answer the following question: "What clinical skills are essential to be learned by the dental students in order to fulfil the generalist profile proposed by the Brazilian National Curriculum Guidelines for Dentistry Undergraduate Courses?". From this question, the authors stablished the dimensions of the study, which were based on cognitive criteria applied to clinical activities proposed by Pessoa and Noro. ${ }^{5}$

From the dimension's definition, sub-dimensions characterized by the main clinical procedures developed by the students were proposed. Dimensions were also based on scientific literature and on consultation of clinical professors of the Dentistry course of the Federal University of Rio Grande do Norte. 
Dimensions and sub-dimensions were validated through the Delphi Method, structured in three rounds of consultations with experts to obtain a collective and qualified opinion about certain questions until a consensus was reached. ${ }^{14,15}$ The Delphi Method allows to create and validate data collection forms, identify professional profiles, and analyze trends and needs in the educational area. It is considered an important tool for evaluation studies and for educational policy planning. ${ }^{14}$

Dental professors from the clinical field, course evaluators from the National Institute for Educational Studies and Research "Anísio Teixeira" (INEP), and active members of the Brazilian Association of Dental Education (ABENO) were considered experts for the present study.

Experts' consultations were conducted according to the Delphi Method between September and December 2018. Each expert received a matrix containing the dimensions and their respective sub-dimensions to which they could make suggestions for improvement, whether by the revision of the sub-dimensions' name or the indication of new ones. ${ }^{16}$ The expert was asked to rate each sub-dimension present in the matrix with a score varying from 0 to 10 , where 0 meant that the sub-dimension should be removed and 10 meant maximum level of importance for a generalist education.

To consolidate the database, the matrixes went through a process of verification, data cleaning and coding, and then stored in Microsoft Office Excel 2010 format. The scores attributed by the experts were consolidated in a database and analyzed descriptively using the mean, median, and standard deviation. The most important sub-dimension had the highest mean and highest median. The standard deviation allowed to estimate the level of consensus, being inversely proportional to the sub-dimension regardless of the importance given to the factor in question.

The present research was approved by the Research Ethics Committee (CEP) of the Federal University of Rio Grande do Norte (UFRN) by the Certificate $2,514,949$. The investigation followed the bioethics principles present in the Resolution $n^{\circ} 466 / 12$ of the National Commission of Ethics in Research (CONEP). Before data collection, the research's goals were explained to the participants ("experts"), who signed the informed consent form.

\section{Results}

To carry out the matrix validation using the Delphi Method, 34 experts were invited. From these, 19 experts went through the three rounds of consultation. The matrix was initially composed of four dimensions (major training areas developed on the field of dental clinic) and 48 sub-dimensions (procedures or activities performed throughout the educational process).

The four validated dimensions were: a) transversal activities, b) diagnosis, c) preventive actions, and d) dental care. In the first round of the Delphi Method, six sub-dimensions with median $\leq 8$ and mean $<8$ with standard deviation $<2$ were excluded. Also, 21 sub-dimensions with median equal to 10 , mean $>9.5$ with standard deviation $<1$ were validated.

In the second round, 21 sub-dimensions that were not validated nor excluded in the first round were sent to experts, who suggested some modifications. In this round, 10 sub-dimensions that presented median equal to 10 , mean $>9$ with standard deviation $<1.5$ were maintained. Two sub-dimensions that presented median equal to 8 , mean $\leq 8$, and standard deviation $>2$ were excluded.

Finally, for the last round of expert consultations, the 9 remaining sub-dimensions were assessed. Six were maintained in the matrix, as they presented median $\geq 9.5$, mean $\geq 8.5$, and standard deviation $<2$.

The sub-dimensions validated by the Delphi Method, clustered by dimension and by consultation round, are shown in Table 1. Similarly, the subdimensions and their respective non-validated criteria are available in Table 2 .

In the preventive actions dimension, the most prominent sub-dimension in the first consultation round was "oral hygiene instruction" $\left(\mathrm{M}_{\mathrm{e}}=9.73\right.$; $\mathrm{SD}=0.7 ; \mathrm{M}_{\mathrm{d}}=10$ ). Of all sub-dimensions appraised, the only one that had maximum importance in this analysis $\left(M_{e}=10 ; S D=0 ; M_{d}=10\right)$ was "clinical exam", which is within the diagnosis dimension. The sub-dimensions "anesthesia" and "dental urgencies", which are both in the dental care dimension, obtained the highest means within their group of evaluators 
Validation of the criteria matrix about the generalist's education in Dentistry Undergraduate Courses

Table 1. Validated sub-dimensions clustered by dimension, with their respective mean $\left(M_{\mathrm{e}}\right)$, median $\left(M_{\mathrm{d}}\right)$, and standard deviation $(S D)$.

\begin{tabular}{|c|c|c|c|c|}
\hline Dimension & Sub-dimension & $M_{e}$ & $M_{d}$ & SD \\
\hline \multicolumn{5}{|l|}{$1^{\text {st }}$ round } \\
\hline \multirow{5}{*}{ Transversal activities } & Biosafety & 9.95 & 10 & 0.2 \\
\hline & Patient-team communication & 9.77 & 10 & 0.6 \\
\hline & Support and humanization & 9.86 & 10 & 0.5 \\
\hline & Ethical principles of dental care & 9.82 & 10 & 0.4 \\
\hline & Medical chart and documentation & 9.68 & 10 & 0.8 \\
\hline \multirow{6}{*}{ Diagnosis } & Diagnosis of dental caries & 9.77 & 10 & 0.7 \\
\hline & Diagnosis of pulp and periapical changes & 9.82 & 10 & 0.5 \\
\hline & Diagnosis of periodontal diseases & 9.68 & 10 & 0.7 \\
\hline & Clinical exam & 10.00 & 10 & 0.0 \\
\hline & Image exams & 9.55 & 10 & 0.9 \\
\hline & Singular therapeutic project & 9.64 & 10 & 0.8 \\
\hline \multirow{2}{*}{ Preventive actions } & Oral hygiene guidance & 9.73 & 10 & 0.7 \\
\hline & Oral cancer prevention & 9.68 & 10 & 0.6 \\
\hline \multirow{8}{*}{ Dental care } & Anesthesia & 9.86 & 10 & 0.5 \\
\hline & Basic oral surgery & 9.68 & 10 & 0.8 \\
\hline & Drug prescription & 9.73 & 10 & 0.6 \\
\hline & Supra and subgingival scaling and root planing & 9.59 & 10 & 0.8 \\
\hline & Restoration of permanent/deciduous tooth & 9.82 & 10 & 0.6 \\
\hline & Minimally invasive restoration treatment & 9.73 & 10 & 0.7 \\
\hline & Non-invasive restoration treatment & 9.64 & 10 & 0.8 \\
\hline & Dental urgencies & 9.86 & 10 & 0.3 \\
\hline \multicolumn{5}{|l|}{$2^{\text {nd }}$ round } \\
\hline \multirow{4}{*}{ Transversal activities } & Ergonomics and four-handed work & 9.19 & 10 & 1.18 \\
\hline & Dental clinic management & 9.33 & 10 & 1.04 \\
\hline & Prophylaxis & 9.62 & 10 & 0.58 \\
\hline & Basic life support & 9.52 & 10 & 0.85 \\
\hline \multirow{2}{*}{ Diagnosis } & Treatment of soft tissue and oral and maxillofacial bone lesions & 9.14 & 10 & 1.04 \\
\hline & Diagnosis of malocclusions & 9.00 & 10 & 1.20 \\
\hline \multirow{2}{*}{ Preventive actions } & Fluoride as prevention & 9.24 & 10 & 1.44 \\
\hline & Deleterious habits guidance & 9.33 & 10 & 1.21 \\
\hline \multirow{2}{*}{ Dental assistance } & Fluoride therapy & 9.52 & 10 & 0.85 \\
\hline & Endodontics of permanent/deciduous teeth & 9.19 & 10 & 1.05 \\
\hline \multicolumn{5}{|l|}{$3^{\text {rd }}$ round } \\
\hline Transversal activities & General health counseling & 9 & 10 & 1.70 \\
\hline \multirow{3}{*}{ Diagnosis } & Laboratory tests & 9 & 9.5 & 1.10 \\
\hline & Diagnosis of temporomandibular joint dysfunctions & 8.7 & 9.5 & 1.58 \\
\hline & Biopsy & 8.6 & 10 & 1.98 \\
\hline Preventive actions & Sealing of pits and fissures & 8.9 & 10 & 1.67 \\
\hline Dental assistance & Removable prosthesis & 8.6 & 9.5 & 1.66 \\
\hline
\end{tabular}

in the first round of the Delphi Method. Both scored 9.86, with median of 10 and standard deviations of 0.5 and 0.3 , respectively. For transversal activities, the most important sub-dimension $\left(\mathrm{M}_{\mathrm{e}}=9.95 ; \mathrm{SD}=0.2\right.$; $\mathrm{M}_{\mathrm{d}}=10$ ) was biosafety.

\section{Discussion}

We currently have 482 operating Dental courses in Brazil and 75 are authorized to start their activities, totaling 557 courses with the possibility of offering 
Table 2. Non-validated sub-dimensions with their respective mean $\left(M_{e}\right)$, median $\left(M_{d}\right)$, and standard deviation (SD).

\begin{tabular}{|c|c|c|c|c|}
\hline Round & Sub-dimension & $\mathrm{Me}$ & Md & SD \\
\hline \multirow{6}{*}{$1^{\text {st }}$ round } & Fixed partial prosthesis & 7.86 & 8 & 2.8 \\
\hline & Treatment of soft tissue and maxillofacial bone lesions & 7.77 & 8 & 1.8 \\
\hline & Indirect restoration & 7.32 & 8 & 2.7 \\
\hline & Interceptive orthodontics & 6.82 & 7 & 3.4 \\
\hline & Dental whitening & 6.73 & 7 & 2.5 \\
\hline & Diagnosis in implantology & 6.55 & 6 & 2.3 \\
\hline \multirow{2}{*}{$2^{\text {nd }}$ round } & Study method analysis & 7.95 & 8 & 2.61 \\
\hline & Periodontal surgery to enlarge clinical crown & 8.0 & 8 & 2.37 \\
\hline \multirow{3}{*}{$3^{\text {rd }}$ round } & Diet counseling & 8.2 & 8.5 & 2.29 \\
\hline & Preventive orthodontics & 8.4 & 8 & 1.32 \\
\hline & Basic treatment of temporomandibular joint dysfunctions & 7.9 & 8 & 2.05 \\
\hline
\end{tabular}

75,417 seats (emec.mec.gov.br). These courses are distributed throughout the national territory, with greater concentration in the Southeast region. Such numbers allow the development of courses with different curricular designs, course load, and educational options. Thus, it is difficult to specify the main characteristic of these courses. However, courses are approved only if they have a pedagogical project consistent with the National Curriculum Guidelines, and thus the teaching is centered on the training of a generalist able to practice in both the Brazilian National Health System (one of the specific competences proposed in the NCG) as well as in the private sector (clinic, ambulatory, emergency service, among others).

The definition of the term "generalist" present in the NGC of all health courses in Brazil is not clear. In the present study, the term was defined based on the learning developed in the clinics of Dentistry undergraduate courses. We sought to get closer to the real concept by the four thematic axes, in this study treated as "dimensions" anchored in the clinical skills and abilities here defined as "sub-dimensions".

The establishment of dimensions and sub-dimensions allowed the construction of a criteria matrix to be appraised by experts according to the Delphi Method. This method is an interactive process that consists of successive rounds of consultation letting the experts review their opinions. The feedback was given to each participant of the evaluation separately from the rest of the team in each round, for the purpose of contrasting their criteria with that of the group and to allow them to change, or not, their oppinion. The application of the matrix required anonymity for the individual responses to establish a consensus based on the statistical processing of the differences and coincidences among individual opinions and their changes throughout the rounds ${ }^{16}$.

The Delphi Method contrasts and combines individual criteria and avoids undesired unilateral decisions by the agent as well as prevalence in the general agreement ${ }^{16}$. The method allowed us to research a group of geographically dispersed participants who could never, otherwise, physically meet to build a consensus, permitting a large number of experts from different regional realities.

The sub-dimensions validated after the first consultation round are seen as "essential" skills and abilities to be carried out by undergraduate students with a view to the generalist clinical practice. They should comprise fundamentally strategic elements within the Pedagogical Project of Dental courses, in order to fulfill premises established by the National Curriculum Guidelines.

The elements ratified in the second and third rounds were understood as "important" skills and abilities for the generalist's training and must be handled differently in the definition of curriculum components of any Dental program, but with less emphasis than those validated previously.

It is suggested that the sub-dimensions that were not validated in the three rounds should be offered as optional curriculum components, complementary activities, research and university extension projects, 
specialization, and update courses, considering that they did not show, according to the experts, the necessary approach to cover the skills and abilities of a generalist.

Despite being addressed simplistically in dental courses, transversal activities received a positive support by the experts, indicating the need for these aspects in the core of any clinical procedure.

Some items in the preventive actions' dimension were not validated by the experts, probably because some of them (diet counselling, preventive orthodontics) are not much discussed yet in Dentistry courses.

Within the scope of transversal activities, biosafety obtained the highest importance according to the evaluators' judgement. Biosafety is a pertinent topic to healthcare training because, besides being relevant to the preservation of biological integrity, it is related to the ethical principles of medical care, which are constantly overlooked in clinical practice. The social systems include biosafety as a practical and cognitive instrument whose objective is the monitoring and prevention of risks outlined from complex processes that act as risk indicators for human and environmental health, highlighting the systemic perspective between mankind/society/nature ${ }^{17}$. In the light of the inseparable triad health/environment/biosafety, the teaching of this thematic is, above all, a moral commitment for both higher education institutions and educators.

Biosafety education, besides its proven importance for risk control and prevention, has a social nature ${ }^{18}$, with a role in the development of the students' sense of responsibility towards their environment and the sense of empathy and commitment. Of note, biosafety was considered an essential sub-dimension still before the COVID-19 pandemic.

Clinical exam, within the diagnosis dimension, obtained maximum importance in this analysis. Technically and didactically, the clinical exam is divided into anamnesis and physical exam of the patient, following the chronological sequence that allows the dentist to be mentally prepared to elucidate a case. Anamnesis is essential to identify symptoms of the patient, representing a subjective exchange process guided by the professional. The physical exam, on the other hand, is objective but it depends on the professional sensibility to perceive the signs given by the patient's body to certain diseases. All information collected in the process must be thoroughly registered on an individual file in order to compose the patient's legal documentation that should be accessed and updated after each appointment, insuring proper continuity and safety of the treatment. ${ }^{19}$

The validation of the "oral cancer prevention" sub-dimension aims to modify a disturbing reality. According to the National Cancer Institute "José Alencar Gomes da Silva", 11,220 new cases of oral cancer in men and 3,500 in women were estimated for each year of the biennium 2018-2019 in Brazil. These values are equivalent to an estimated risk of 10.86 new cases per 100,000 men and 3.28 per 100,000 women, the $5^{\text {th }}$ and $12^{\text {th }}$, respectively, most frequent cancer types. The evaluators' concern is based on the asymptomatic nature of oral tumors in early stages, which may mimic common benign conditions, ${ }^{20}$ and their early detection is key for a more favorable prognosis and greater chance of cure.

The evaluators indicated the high importance of integrating contents for the solution of an oral disease that is recurrent in society. The sub-dimensions of dental caries diagnosis, pulp and periapical changes, and periodontal diseases, the most common conditions in clinical practice, were related to conducts and processes that allow their diagnosis (patient-team communication, support and humanization, ethical principles, medical chart and documentation, image exams), their treatment/ rehabilitation (individual therapeutic project, dental urgencies, anesthesia, basic oral surgery, supra and subgingival scaling and root planing, restoration of permanent/deciduous teeth, minimally invasive and non-invasive restoration treatment, drug prescription), and their prevention (oral hygiene guidance).

Some dental care skills and abilities that are more specific within their thematic areas (dental whitening, fixed partial dental prosthesis, and treatment of soft tissue and maxillofacial bone lesions) were left out of the matrix after the first round of evaluation, which reinforces the thesis that the generalist dentist should be trained to face the most significant oral health problems from an epidemiology perspective.

In situations in which the students are trained by traditional methods of teaching, it is not wise to 
demand different professional conducts. It is known that there are shortcomings in the training of healthcare professors that demand technical knowledge specific to the profession, didactic mastery, and conceptual understanding of the teaching processes. The coordination of technical and pedagogical knowledges, conceptualized as the pedagogical knowledge of the content ${ }^{21}$ is key to the training of students with scientific knowledge, aware of their profession's socio-political function to be exerted. ${ }^{22}$

The professor's professionalization becomes a challenge, and it aims to allow reorganization of the practices in higher education institutions, especially to guarantee the effectiveness of critic-reflexive education, integral training, knowledge composition from the articulation and insertion of new contents, teaching strategies, and creation of new curricular designs.

According to Marques et al., ${ }^{23}$ the ethical reflexivity in a career is a psychological development process with cognitive structural support that allows a person to be able to prospect his decisions and life project and the ways to execute them. By exerting reflexivity, professionals can make projects and define strategies based thier social circumstances. Therefore, to think, research, and understand the training of professors as a space constituting the knowledge requires a revision of concepts and theories about the pedagogical practice. ${ }^{24}$

The results of the present study should not be confused with the validation of minimum contents, which could transmit the idea of a minimum curriculum, present in all Dentistry courses in the context before the NCG, which did not admit curriculum flexibility. Competences and abilities refer to the idea of mobilizing a set of cognitive resources (knowledge, skills, information, etc.) to resolve with pertinence and effectiveness different situations. ${ }^{25}$

\section{Conclusion}

The results of this study, certified by the several actors involved in the construction and validation stages, represent a differentiated alternative for the construction of an innovative curricula in Dentistry, aimed at the training of general practitioners to act in the perspective of humanized, effective, and high-quality care.

The study also highlights the challenge of professors, recognized in their clinical specialties, to play the role of tutors, assuming full responsibility for supervising clinical competences and abilities classified as "essential", during the training of general dentists.

Therefore, suggestions for change should not be restricted to the methodological field but should guide a real transformation in the pedagogical culture of educational institutions. Focusing on this objective, studies based on the Delphi Method can contribute significantly, considering the scarcity of studies in the field of professor training and public policies in Brazilian education. ${ }^{14}$

The clinical courses in Dental schools must provide the opportunity for the student to put into practice the scientific knowledge built collectively, training dentist that are able to meet individual and collective demands, with the ability to create solutions in the face of challenges. ${ }^{26}$

\section{References}

1. Ministério da Educação (BR). Conselho Nacional de Educação. Diretrizes Curriculares Nacionais dos Cursos de Graduação em Farmácia e Odontologia. Diário Oficial União. 2001 dez 7.

2. Freitas SF, Calvo MC, Lacerda JT. [Collective health and new curricular directives in dentistry: a proposal for undergraduate courses]. Trab Educ Saúde. 2012 Oct;10(2):223-34. Portuguese. https://doi.org/10.1590/S1981-77462012000200003

3. Furtado JP. [Reference teams: an institutional arrangement for leveraging collaboration between disciplines and professions]. Interface (Botucatu). 2007 Aug;11(22):239-55. Portuguese. http://doi.org/10.1590/S1414-32832007000200005

4. Nascimento DD, Oliveira MA. [Professional competences and the training process in a multi-professional internship in family health]. Saude Soc. 2010;19(4):814-27. Portuguese. https://doi.org/10.1590/S0104-12902010000400009

5. Pessoa TR, Noro LR. Pathways for graduation evaluation in dentistry: logical model building and validation criteria. Cienc Saúde Coletiva. 2015 Jul;20(7):2277-90. http://doi.org/10.1590/1413-81232015207.13182014 
Validation of the criteria matrix about the generalist's education in Dentistry Undergraduate Courses

6. Kriger L. O diferente é formar o generalista. Rev Clin Pesq Odontol. 2005;1(4):7-9.

7. Chehuen Neto JA, Sirimarco MT, Cândido TC, Ulhoa CM, Reis BP, Lima VM. General medical education: perception of professional and student. HU Rev 2014;40(1-2):13-23.

8. Ministério da Saúde (BR), Ministério da Educação (BR). The adherence of undergraduate courses in nursing, medicine and dentistry to the national curricular guidelines. Brasília, DF: Ministério da Saúde, 2006.

9. Lazzarin HC, Nakama L, Cordoni L. Perceptions of dentistry teachers in the teaching and learning process. Cienc Saúde Coletiva. 2010 Jun;15(1):1801-10. https://doi.org/10.1590/S1413-81232010000700092

10. Toassi RF, Souza JM, Baumgarten A, Rosing CK. [Curricular evaluation of higher education in dentistry: a discussion about the effects of curriculum changes on health care training in Brazil]. Rev. ABENO. 2012;12(2):170-7. Portuguese. https://doi.org/10.30979/rev.abeno.v12i2.120

11. Pizzato E, Garbin CA, Garbin AJ, Saliba NA. The role of the professor in dental education. Saúde Debate. 2004;28(66):52-7. Available from: https://scholar.google.com.br/citations? user=ZEGI57wAAAAJ\&hl=pt-BR

12. Natal S, Samico I, Oliveira LG, Assis AM. Availability study of the human resources formation network of Secretary of Health Surveillance of Health Ministry. Cad Saude Colet. 2010;18(4):560-712010.

13. Oliveira CM, Cruz MM, Kanso S, Reis AC, Lima A, Torres RM, et al. Evaluability of the Program to Value Primary Healthcare Professionals (PROVAB): management challenges. Cienc Saúde Coletiva. 2015;20(10):2999-3010. http://doi. org/10.1590/1413-812320152010.13322014

14. Antunes MM. Delphi technique: research methodology for education in Brazil. Rev Educ PUC-Camp. 2014 Jan/Apr;19(1):63-71. https://doi.org/10.24220/2318-0870v19nla2616.

15. Vendruscolo C, Prado ML, Kleba ME. Teaching-Service integration within the National Professional Health Education Reorientation Program. Cienc Saúde Coletiva. 2016 Sep;21(9):2949-60. http://doi.org/10.1590/1413-81232015219.12742015

16. Valdés MG, Marín MS. Use of the Delphi method in investigations on health published in Cuban scientific magazines. Rev Cuba Inf Cienc Salud. 2013;24(2):133-44.

17. Navarro MB, Ardions JP, Soares BE, Cardoso TA. [The environmental crisis and the cognitive and analytical scope of biosafety]. Cienc Cogn. 2016 Mar;21(1):23-32.

18. Santos MJ, Pereira ME, Machado GC, Shubo TC, Claudia J. [Biosafety teaching and environment: an experience in the Oswaldo Cruz Foundation]. Cienc Cogn. 2011 Dec;16(1):193-205.

19. Passarelli DH. Atlas de estomatologia: casos clínicos. São Paulo: Elsevier Brasil; 2017.

20. Instituto Nacional do Câncer José Alencar Gomes da Silva - INCA. Estimativa 2018: incidência de câncer no Brasil. Rio de Janeiro: INCA; 2017. [cited 2020 Jan 22]. Available from: http://wwwl.inca.gov.br/estimativa/2018/

21. Backes VM, Medina Moya JL, Prado ML. The construction process of pedagogical knowledge among nursing professors. Rev Latino-Am Enfermagem. 2011 Mar-Abr; 19(2):421-8. http://doi.org/10.1590/S0104-11692011000200026

22. Moraes GS, Mecca LESA, Jitumori RT, Dalmolin AC, Huller D, Wambier DS, et al. Didactics in dental education: professors' perceptions. Rev ABENO. 2018 Apr;18(2):27-36. https://doi.org/10.30979/rev.abeno.v18i2.451

23. Marques C, Silva AD, Oliveira IM, Silva F, Taveira MC. [Career ethical reflexivity in different phases of the life cycle]. J Child Adolesc Psychol. 2018;8(1):81-91. Portuguese.

24. Rocha RB, Arruda MP, Andrade IC. [Training of teachers in service: narratives of self-production and the world]. Cad Pesq. 2018;25(1):95-108. Portuguese. https://doi.org/10.18764/2178-2229.v25n1p95-108

25. Perrenoud P. [Professionalization of the teacher and the development of learning cycles]. Cad Pesqui. 1999 Nov;108(108):7-26. Portuguese https://doi.org/10.1590/S0100-15741999000300001

26. Melani A, Pestana SR, Zilbovicius C, Martins J, Frias AC, Junqueira S. Trabalho de campo em saúde bucal: um contexto da relação ensino-serviço-comunidade. Rev Grad USP. 2018 Jun;3(1):101-5. https://doi.org/10.11606/issn.2525-376X.v3ilp101-105 